\title{
Influenza Infection Leading to Cardiac Complications
}

\author{
Supriya Bisht ${ }^{1}$, Weam Alnayem ${ }^{1}$, Ahmed Awad ${ }^{1}$, Joseph Mahgerefteh ${ }^{1}$ and Ratna Basak ${ }^{1,2}$ \\ ${ }^{1}$ Department of Pediatrics, Brookdale Hospital and Medical Center, USA \\ ${ }^{2}$ Department of Pediatrics, Flushing Hospital and Medical Center, USA
}

Submission: March 16, 2020 Published: April 13, 2020

*Corresponding author: Supriya Bisht, Department of Pediatrics, Brookdale Hospital and Medical Center, New York, USA

\section{Abstract}

Influenza is a common viral illness which usually present with fever, body ache, headache, cough and sore throat. The clinical recovery is usually seen within two weeks. Rarely, patients may develop life threatening cardiac complications which can be due to inflammatory response to the infection. Authors present a case of 10-year-old girl initially admitted for influenza infection, who later on developed myo-pericarditis.

Keywords: Influenza; Complications; Cardiac; Pediatric

\section{Case Report}

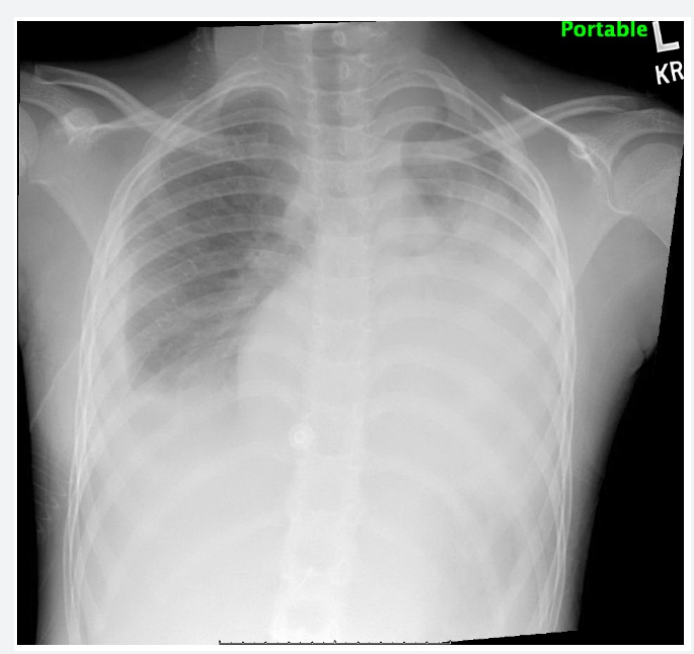

Figure 1: $\mathrm{X}$ ray chest showing extensive bilateral pneumonia (left $>\mathrm{rt})$, with moderate bilateral pleural effusions.

A 10 years old girl without a significant past medical history, presented to the Emergency Department with 3 days history of myalgia, dizziness, headache, poor oral intake and one episode of watery diarrhea. She tested positive for Influenza A (she had not received influenza vaccine). She was discharged home on supportive treatment. The following day, she returned to the ED with worsening headache, body ache, and decreased oral intake and urine output. She was admitted for intravenous rehydration. On admission, she looked lethargic with dry mucus membranes and poor peripheral perfusion. She was tachycardic (130/min), hypotensive $(88 / 64 \mathrm{mmHg})$, her temperature was $35.6 \mathrm{deg}$ C, Labs were significant for hyponatremia $(127 \mathrm{meq} / \mathrm{L})$, hyperkalemia 
$(5.9 \mathrm{meq} / \mathrm{l})$, and high venous lactate $(5.3 \mathrm{mmol} / \mathrm{L})$ with normal $\mathrm{CBC}$, kidney functions and $\mathrm{C}$ reactive protein. Initial Chest-X-Ray showed left lower lobe infiltrates. She received normal saline bolus, oseltamivir and ceftriaxone. Due to hypotension and tachycardia and concern for clinical sepsis, intravenous vancomycin was added for broader coverage. The patient required 3 fluid boluses of $20 \mathrm{ml} / \mathrm{kg}$ to maintain her blood pressure, but hyponatremia (131meq/L) persisted. The urine osmolality was higher (330milliosmoles/L) than serum osmolality (283milliosmoles/L), raising the concern for syndrome of inappropriate antidiuretic hormone. On the $2^{\text {nd }}$ day of admission, she was noted to have respiratory distress, with reduced air entry on both sides (left side $>$ right side). Repeat Chest-X-ray (Figure 1) and ultrasound (Figure $2 \& 3$ ) revealed progression of pneumonia with bilateral pleural effusions. Electrocardiogram showed low voltage QRS (Figure
4). Troponin I was raised $(0.525 \mathrm{ng} / \mathrm{ml}$, normal range was 0.00 $0.034 \mathrm{ng} / \mathrm{mL}$ ) with high Pro-BNP (2020pg/ml). Echocardiogram demonstrated large pericardial and pleural effusions with normal ejection fraction. Respiratory support with Bilevel Positive Airway Pressure (BIPAP) of 12/6 was started. Bilateral chest tubes were inserted with drainage of $400 \mathrm{ml}$ of pleural fluid and pericardiocentesis revealed $200 \mathrm{ml}$ of serous fluid. Over the next 48 hours, she showed significant clinical improvement and her respiratory support was weaned. Blood, pleural and pericardial fluid cultures was negative. She received oseltamivir for 5 days, intravenous antibiotics for one week and was discharged home. She was followed up at the cardiology clinic, 1-week post discharge and after 6 months. She remained clinically well with normal EKG and echocardiographic findings.

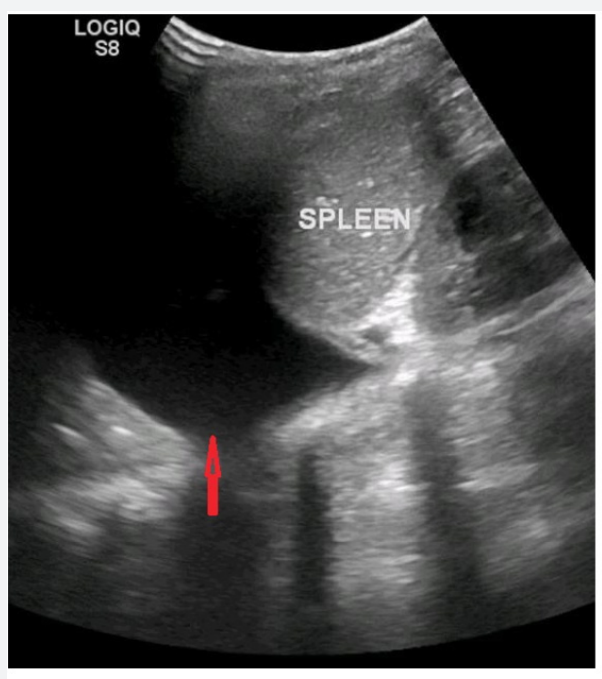

Figure 2:Ultrasound chest suggesting pleural effusion- left side.

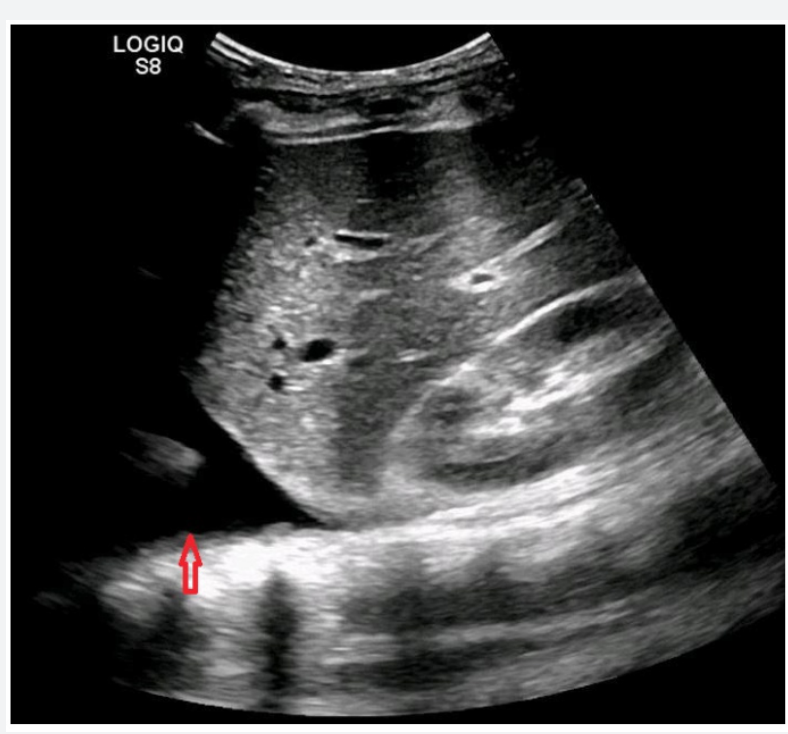

Figure 3: Ultrasound chest suggesting pleural effusion- right side. 


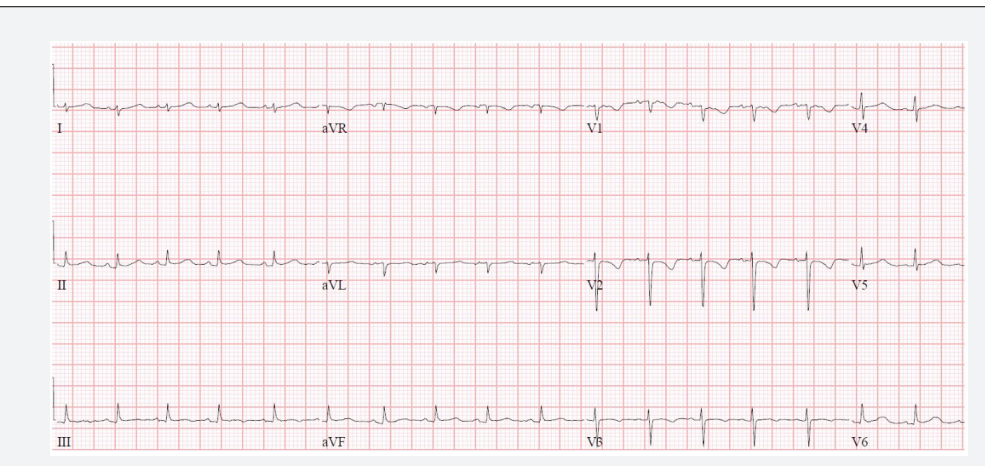

Figure 4: EKG suggesting low voltage QRS

\section{Discussion}

Influenza is a common viral illness during winter season presenting with fever, body ache, headache, cough and sore throat. The clinical recovery is usually seen within two weeks. Some patients may develop complications, few of which can be life-threatening [1,2]. The infection can trigger an extreme inflammatory response in the body which can effectively eliminate the infection. However, a prolonged and excessive inflammatory response may result in complications such as systemic inflammatory response syndrome. Influenza virus can also significantly interact with the immune system, leading to severe sepsis or to a secondary bacterial infection [1]. The most common complication in an intensive care setting is secondary bacterial infection, respiratory failure and ARDS. Severe hypoxemia and cardiovascular failure which can lead to multi organ failure [3]. Rarely influenza infection can cause myocarditis, pericarditis, myo-pericarditis, pericardial effusion and even cardiogenic shock [4,5]. Myocarditis in children may often be missed, as the initial presentation in infants may be nonspecific like fever, poor feeding, irritability, tachycardia and cyanosis. Older children may also complain of chest pain, shortness of breath, abdominal pain, myalgia, arthralgia, palpitations, cough or edema [6]. The spectrum of presentation may vary from being completely asymptomatic to dyspnea, arrhythmias, and florid congestive heart failure leading to cardiogenic shock $[7,8]$. Collection of large amount or rapid accumulation of fluid in the pericardium may lead to pericardial tamponade [5]. The EKG changes of ST elevation, T wave inversion, and conduction block. Elevation of creatinine kinase (CPK-MB), and troponins confirm the diagnosis of myocarditis in this setting. ECHO can reveal transient wall edema with reduced wall motion, decreased cardiac chamber size and pericardial effusion [9]. The pathological confirmation of myocardial inflammation is by endomyocardial biopsy, not done due to its invasive nature. Oral oseltamivir and inhaled zanamivir are recommended for treatment and prevention of influenza. The initiation of oseltamivir within the first 48 hours for patients who have severe, complicated, or progressive illness has significantly decreased the mortality rate. The use of oseltamivir even four days after the onset of symptoms have lead to better outcomes [3]. Management of myocarditis includes hemodynamic support with combinations of vasopressors and inotropes. Large pericardial effusion need drainage. ECMO may be required in complicated cases. The role of IVIG is controversial $[7,9]$. The mortality with fulminant myocarditis is as high as $40 \%$ [7]. Timely diagnosis and adequate supportive management is needed for optimum clinical outcome. Influenza vaccination is the only protection against the infection and its complications, which should be strongly encouraged

\section{Conclusion}

The clinical presentation of Influenza associated myocarditis may be nonspecific. The lack of cardiac symptoms may cause a delay in the diagnosis. Pediatricians should recognize the early cardiac signs to avoid the possibility of circulatory decompensation.

Influenza mortality is high despite antiviral and supportive treatment. Early initiation of oseltamivir may lead to better clinical outcomes.

\section{References}

1. Florescu DF, Kalil AC (2014) The complex link between influenza and severe sepsis. Virulence 5(1): 137-142.

2. CDC (2020) Flu symptoms and diagnosis.

3. Çiftçi E, Karbuz A, Kendirli T (2016) Influenza and the use of oseltamivir in children. Turkish Archives of Pediatrics 51: 63-71.

4. Gross ER, Gander JW, Reichstein A, Cowles RA, Stolar CJ, et al. (2011) Fulminant pH1N1-09 influenza-associated myocarditis in pediatric patients. Pediatr Crit Care Med 12(2): 99-101.

5. Koranyi K, Yontz D, Rohrer Z, Leber A, Ramilo O (2010) Pericardial effusion complicating novel influenza A (H1N1) infection in an infant. Pediatr Infect Dis J 29(8): 782-783.

6. Farinha IT, Miranda JO (2016) Myocarditis in Paediatric Patients: Unveiling the Progression to Dilated Cardiomyopathy and Heart Failure. Journal of cardiovascular development and disease 3(4): 31.

7. Batra AS, Lewis AB (2001) Acute myocarditis. 2001. Curr Opin Pediatr 13: 234-239. 
8. Aykaca K, Ozsurekcia Y, Kahyaoglub P, Basaranoglua ST, Ertugrul I et al. (2018) Myocarditis associated with influenza infection in five children. Journal of Infection and Public Health. 11(5): 698-701.
9. Ukimura A, Satomi H, Ooi Y, Kanzaki Y (2012) Myocarditis associated with influenza a H1N1pdm 2009. Influenza Res Treat.
This work is licensed under Creative

Commons Attribution 4.0 Licens

DOI: 10.19080/AJPN.2020.09.555823
Your next submission with Juniper Publishers will reach you the below assets

- Quality Editorial service

- Swift Peer Review

- Reprints availability

- E-prints Service

- Manuscript Podcast for convenient understanding

- Global attainment for your research

- Manuscript accessibility in different formats

( Pdf, E-pub, Full Text, Audio)

- Unceasing customer service

Track the below URL for one-step submission

https://juniperpublishers.com/online-submission.php 